\title{
Muros e ruas como vitrine, palco e palanque. De Nazza à Pato, de Buenos Aires ao Rio.
}

\author{
Roberta Filgueiras Mathias ${ }^{1}$ Michele Petruccelli Pucarelli²
}

Resumo: Nesse artigo analisamos o trabalho de dois artistas sul-americanos, Nazza e Wallace Pato, cujas obras debatem questões sociais e identitárias, territoriais, violência urbana, deslocamentos e migrações. Suas obras estão nos muros de várias cidades como vitrines de suas artes, mas também como palanques e espaço de reflexão em permanente diálogo entre artes e política.

Palavras-chave: artivismo, Nazza, Wallace Pato, América Latina

\section{Walls and streets as a showcase, stage and platform. From Nazza to Pato, from Buenos Aires to Rio.}

\begin{abstract}
In this article we analyze the work of two South American artists, Nazza and Wallace Pato, whose works discuss social and identity issues, territorial issues, urban violence, displacement and migration. His works are on the walls of several cities as showcases of his arts, but also as platforms and spaces for reflection in a permanent dialog between the arts and politics.
\end{abstract}

Keywords: artivism, Nazza, Wallace Pato, Latin America

1 Mestre em Filosofia pela PUC-SP. Pesquisadora na área de Antropologia Urbana estudando periferias latinoamericanas. Iniciou o Doutorado em Antropologia Social pela Universidad Nacional de San Martín (Buenos Aires) e continua os estudos no Departamento de Ciências Sociais da UERJ (PPCIS). Professora convidada no Curso de Especialização em Fotografia e Imagem (IUPERJ) Integrante do LEARCC-coordenado pela Professora Doutora Ana Paula Pereira da Gama Alves Ribeiro. Membro da ABA. Universidade do Estado do Rio de Janeiro (PPCIS/UERJ) E-mail: mathias.beta@gmail.com. ORCID: https://orcid.org/0000-0002-8715-4998. Lattes iD: http://lattes.cnpq. br/3104292258472067. Rio de Janeiro, Brasil

2 Professor Adjunto - Curso de Jornalismo - Departamento de Comunicação - Instituto de Artes e Comunicação Social - Universidade Federal Fluminense - GCO/IACS/UFF, Niterói - Rio de Janeiro, Brasil. Coordenador do Projeto @liex.uff - Laboratório de Imagens Expandidas: uma rede de comunicações e afetos, através da articulação entre fotografia, artes, redes e tecnologia. Possui Doutorado em Artes Visuais - PPGAV/UFRJ e Mestrado em Comunicação e Cultura PPGCOM/UFRJ. Universidade Federal Fluminense (GCO/IACS/UFF). E-mail: michelepucarelli@id.uff.br ORCID: https://orcid.org/0000-0001-9345-4463. Lattes iD: http://lattes.cnpq.br/7444725694597139. Rio de Janeiro, Brasil 
Se as ruas de algumas cidades e capitais latino-americanas sempre foram palcos de manifestações populares em momentos de descontentamento e revoltas contra seus governos, os muros e empenas destas mesmas cidades foram, ao longo das últimas décadas, se transformando em eloquentes vitrines de comunicação artística para artistas muralistas, que fazem delas palanques de reverberação sobre questões sociais, políticas e econômicas de cada região.

O termômetro das inquietações populares sobe e desce em função da história particular de cada país, mas cabe ressaltar que 2019 foi um ano tenso na América Latina como um todo e nada parecer indicar que 2020 será muito diferente. Acontecimentos impactantes não faltaram: gigantescas manifestações de rua em várias cidades importantes, eleições turbulentas, renúncias de presidentes recém-eleitos, autoproclamação de um novo presidente mesmo existindo um presidente eleito, tensões relativas aos processos de migração nas fronteiras, suicídio de ex-presidente acusado de corrupção e no fim do ano o aviso da probabilidade de uma pandemia global , em função de um vírus respiratório que surgiu na China em dezembro e provavelmente irá se espalhar por todo os países do mundo. (D'ÁVILA, 2020)

A estagnação econômica geral dos últimos anos, junto às crises de representatividade política em inúmeros países da América Latina deixam a região inquieta. Uma mobilização popular ainda mais intensa nas ruas de alguma capital latino-americana, com o agora natural e consequente compartilhamento nas redes sociais, poderá vir a ser o estopim de um efeito-contágio para que novas manifestações se precipitem nos países vizinhos. Apesar da impossibilidade de se prever o futuro, algumas configurações políticas, econômicas e sociais atuais ajudam a compreender o porquê de certa apreensão com o cenário político latino-americano de 2020.

A Argentina, um dos nossos mais importantes parceiros comerciais, consolidou na última votação presidencial o retorno da esquerda ao poder, elegendo Alberto Fernandez, mas, conforme relata a colunista Sylvia Colombo, correspondente em Buenos Aires da Folha de São Paulo:

Se depois de alguns meses o novo governo não conseguir arrefecer os problemas sociais decorrentes da inflação de $55 \%$ ao ano, é possível que retornem panelaços e protestos (COLOMBO, 2019)

O Chile teve massivas mobilizações e protestos sociais pelas ruas da capital Santiago. A Colômbia convive com o aumento da violência pelo retorno 
de guerras internas de grupos paramilitares, além de crises sociais com a chegada de mais de um milhão de venezuelanos. Na Bolívia, em novembro de 2019, após uma eleição conturbada, Evo Morales renunciou ao cargo de presidente e pediu asilo político. O ex-presidente do Peru, Alan Garcia, se suicidou após receber ordem de prisão, acusado de corrupção ativa no caso Odebrecht. No Equador, após a imposição de um pacote econômico do governo de Lenín Moreno, milhares foram às ruas protestar contra a exclusão social, desigualdade econômica, racismo, cortes na saúde e educação, desemprego e crescente violência. E, para encerrar esse breve resumo do contexto político latino-americano da atualidade, no México, o governo de Andrés Manuel López Obrador não conseguiu diminuir os números da corrupção, dos homicídios e da estagnação econômica. (CASTIGLIONI, 2019)

\section{Artes e política nas ruas da América do Sul - Experiência contemporânea}

Apesar de um cenário em ebulição, é importante destacar que, se as particularidades sociais e econômicas de cada país determinam razões diferentes para o início de suas mobilizações populares, parece que as desigualdades sociais e os abusos de poder estão entre os questionamentos comuns a todos. Esse cenário acentua a sensação cada vez mais frequente de falta de expectativas profissionais e econômicas, que recai de modo mais frequente nas populações de baixa renda dos jovens latinos que ficam pelas ruas. Esta configuração de desequilíbrio social e econômico ajuda a entender, em parte, não só o aumento da violência urbana, como da percepção geral de que o medo se tornou parte permanente da experiência cotidiana contemporânea de muitas cidades latino-americanas.

Essas transformações, que afetam a sociedade como um todo, também se aplicam ao universo da arte e nos levam à emergência de refletir sobre o todo e, particularmente, sobre as manifestações artísticas em tempos de crises. Afinal, são os artistas com suas antenas de sensibilidade que costumam inserir no espaço cotidiano as imagens que indicarão novos caminhos e fronteiras visuais a fim de refletir o desequilíbrio em andamento na ordem imperante, além de criarem novas forma de encontro cotidiano.

A arte busca não reduzir o que é útil à esfera do proveito. Ao fazer isso, a arte além de questionar-se, põe um ponto de interrogação em outras formas de organizar o social. Os artistas assumirão as questões antropológicas [...] A arte como instaladora de dúvidas sobre a existência. (CANCLINI, 2016, p. 88) 
Dentro desse contexto cabe refletir sobre o modo como as obras de artistas que tem a questão social como tema podem reinventar visualmente as atuais narrativas. Além disso, cabe indagar: de que maneiras se pode ultrapassar a mera descrição dos fatos para revelar imagens que não conseguimos mais avistar e, assim, permitir que vejamos o que se tornou invisível a muitos?

A proposta deste artigo é analisar, através das obras e trajetórias de dois artistas sul-americanos, não só as potências e possibilidades de enfrentamento estético em tempos políticos extremistas pelos quais o continente passa, mas também as relações simbólicas e sociais expressas em suas obras. Os dois artistas analisados entendem a rua como mural e pretendem atingir a um público maior do que aquele que frequenta ambientes convencionais de arte.

Muito já se falou sobre a cooptação do grafite pelas galerias - podemos citar aqui a Bienal de Arte de São Paulo, de 2010, que teve alguns de seus muros grafitados, mas que, de alguma forma, amplificou uma discussão que deu origem à Bienal de Grafite. Os dois artistas em questão, Wallace Pato, brasileiro, e Nazza, argentino, recusam a galeria e espaços como museus e galerias como seus ambientes principais. Ambos julgam que a obra de caráter político que produzem deve ser vista nos mais diversos espaços da cidade.

\section{Passado e presente das migrações nordestinas}

Wallace Pato não é nordestino, nasceu no Rio de Janeiro. Mas ao morar em Ramos e transitar pelos bairros vizinhos, observava a grande população de migrantes. Pato, que já grafitava pelas ruas da Zona Norte, passou a olhar para essa cultura com mais atenção e fez deste seu principal foco de trabalho. A própria técnica também mudou ao adotar o pincel ao invés das latas de tinta. $\mathrm{O}$ artista rapidamente desenvolveu uma maneira própria de retratar expressões faciais e nuances de luz. Artista inquieto, Wallace parece novamente estar mudando de abordagem ao se aproximar de pinturas quase expressionistas. No entanto, os rostos negros e pardos continuam como protagonistas em seu trabalho. Em seu instagram @wallace.pato, ele expõe: "Minha intenção na pintura é ser porta-voz de quem nunca foi ouvido, é dar voz a quem nunca teve ou que é ofuscado. " (PATO, 2018) 
Pato visitou recentemente Crato e Juazeiro registrando com sua arte através dos pincéis os moradores nas paredes de suas casas, além de registrar migrantes Nordestinos que se estabeleceram no Complexo do Alemão, Maré e contornos. Suas obras tomam, principalmente, além dos muros da Maré e do Complexo do Alemão, os bairros da região Norte do Rio de Janeiro: Bonsucesso, Ramos, Olaria e Penha. Pato se diz cria de Ramos, já que nasceu e ainda vive nesse bairro. Ele faz questão de registrar momentos do cotidiano de um morador da Zona Norte e tenta desconstruir o estigma da violência na região, mas vai além.

Em seu resgate à cultura Nordestina, o artista não somente vai atrás da-

Figura 1 Wallace Pato, Dona Albertina, muralismo, $3,5 \mathrm{x}$ 2,80 mts, 2018, Crato, Ceará. Fonte: https://www. instagram.com/ wallace.pato/
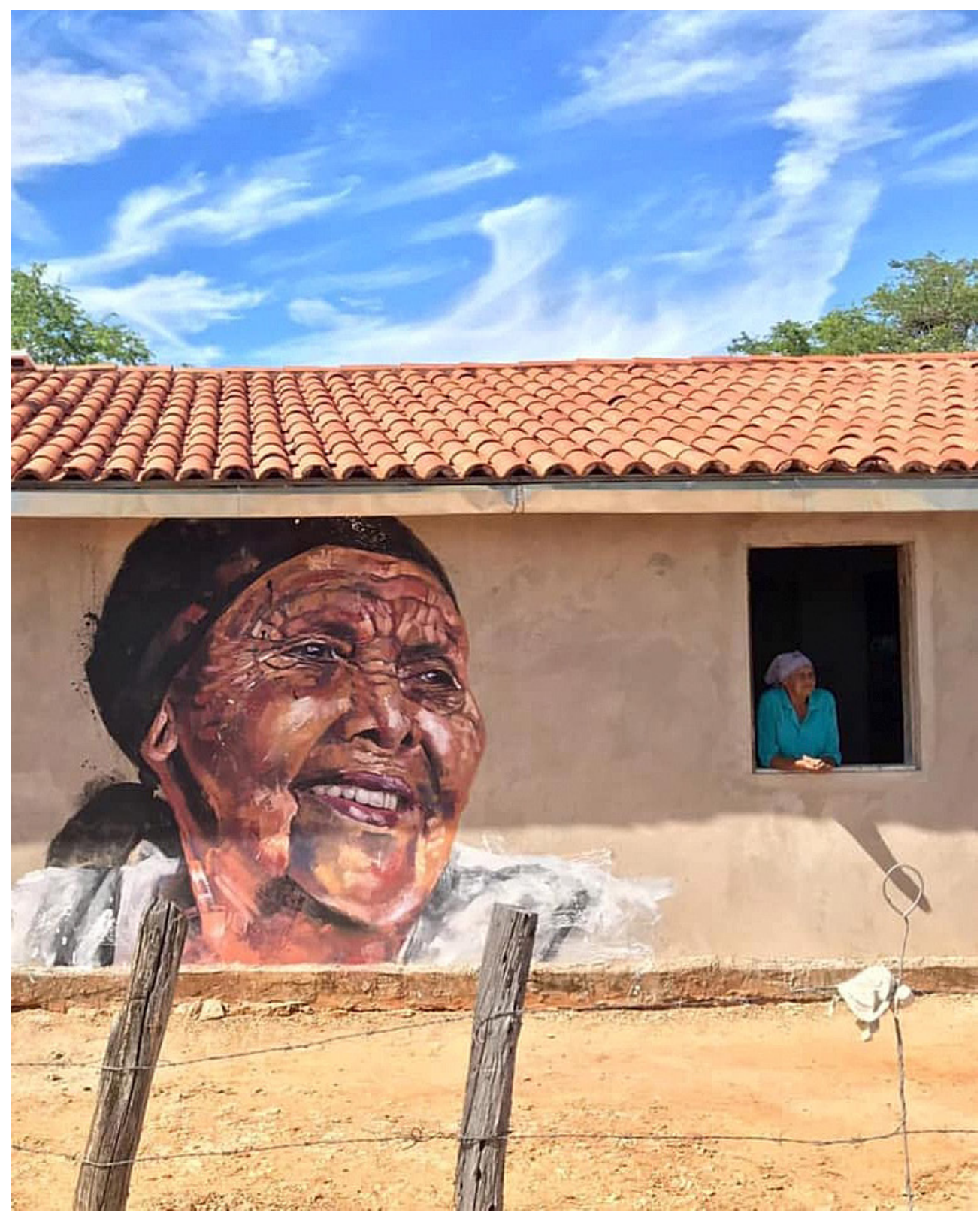
quilo que está na essência de algumas das grandes comunidades do Rio de Janeiro - que têm uma grande população de migrantes, mas procura também estabelecer uma ponte entre os que vieram para o Rio de Janeiro e os que permaneceram. Essa relação complexa entre passado e presente pode ser observada na maneira como o artista procura desenvolver a estética de suas obras (utilizando o pincel nos muros), mas também em seu discurso. Em conversa no Sesc Ramos, disse que, inicialmente, registrava os moradores do complexo que eram seus vizinhos e que a relação com a cultura regional vem desses encontros com os migrantes, pois, até então, ele nunca havia visitado o Nordeste.

Figura 2 Wallace Pato, Atemporalidade, técnica: muralismo, $5,80 \times 3,20$ mts. Local: Mural do Museu da Arte Moderna MAM, Rio de Janeiro. Fonte: https:// www.instagram. com/wallace. pato/

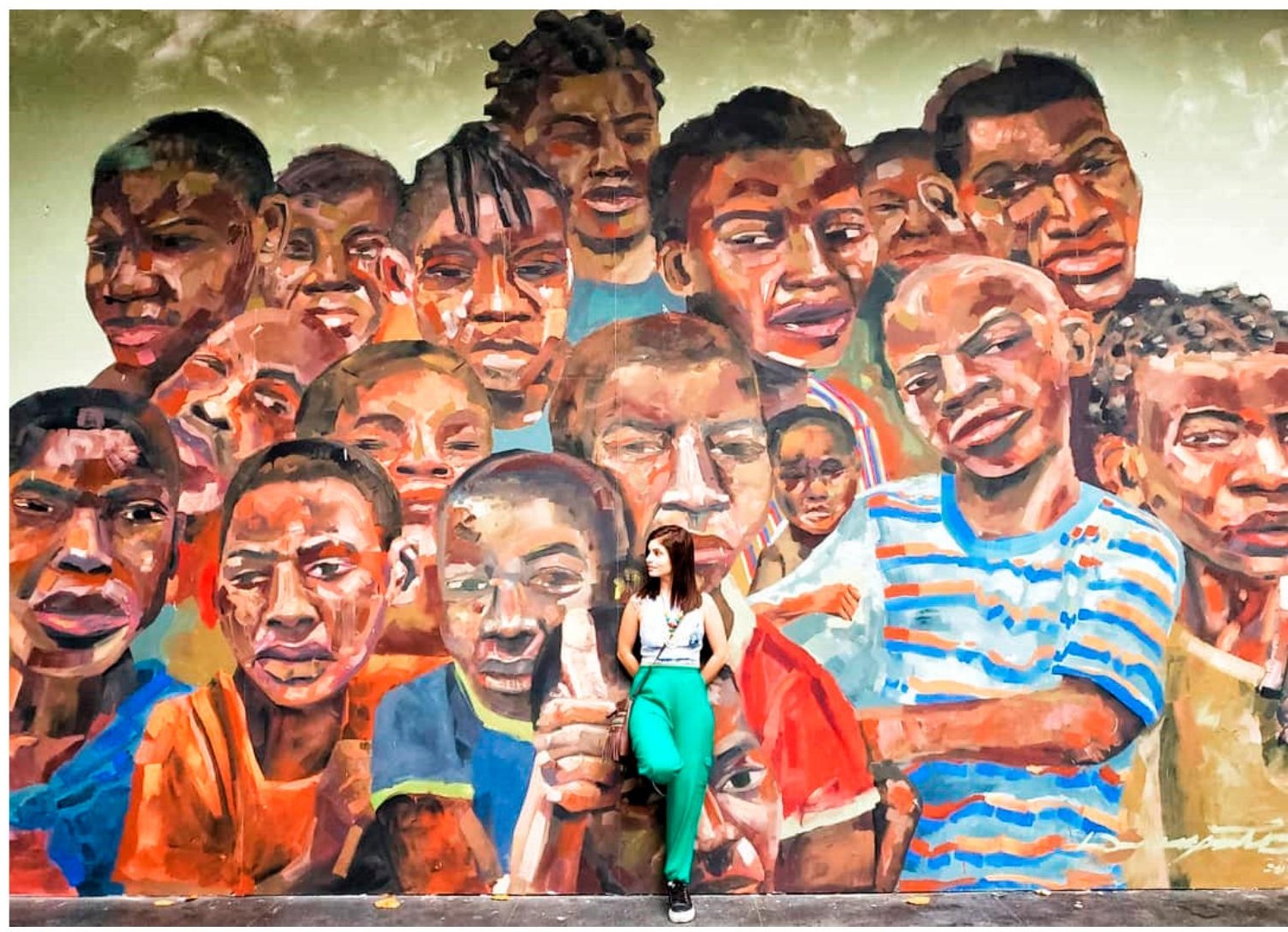

Nesse sentido, a questão territorial pode ser ressignificada a partir de seus moradores e de suas culturas originárias. Dessa forma, o artista recria o imaginário sobre o Nordeste profundo e faz com que imagens de seus moradores e de suas rotinas circulem pelo Rio de Janeiro, aproximando visões distantes tanto física quanto culturalmente. Sabemos da forte presença de nordestinos que a região da Zona Norte da cidade possui e, é essa presença que Pato busca sublinhar com suas obras na rua. Presença esta que tomou novas formas porque, após as visitas iniciais, o artista assumiu a postura de morar entre o Rio e cidades do Nordeste. 


\section{Prática artística e ativismo político}

Nazza, por outro lado, reforça a imagem dos povos originários na construção cultural e política da Argentina. Em seus stencils, Nazza (tag- assinatura deixada pelo artista em suas obras), nascido na província de La Matanza - Buenos Aires, trabalha desde meados dos anos $90 \mathrm{com}$ as culturas e imagens de indígenas, negros, mulheres e crianças em situação de rua. $\mathrm{O}$ artista procura imprimir as obras em diversos locais da cidade de Buenos Aires e suas províncias provocando incômodo e reflexão.

Suas obras se encontram na encruzilhada entre a prática artística e o ativismo político. Suas composições se concentraram em questões como os desaparecidos argentinos, as avós e mães da Plaza de Mayo (a associação de mulheres cujos filhos e netos desapareceram durante o mesmo período), questões sociais como o feminicídio \# ni una a menos, e sobre destruição silenciosa das culturas e povos indígenas da Argentina

Cada uma de suas intervenções aborda uma questão específica, com o objetivo de inserí-la na esfera pública. Em alguns de seus stencils mais famosos, Nazza utiliza frases como: Mi hambre es tu moda, Honra tu lugar e Mujer bonita es la que lucha. Atualmente, o artista circula por países da América do Sul deixando impressos seus stencils nas ruas e participando de oficinas e exposições.

Figura 3 Nazza, Mi hambre es tu moda, muralismo, 2,20 x 1,80 mts. Estação Subt. Linea B Angel Gallardo. 2016. Foto Martha Cooper, Buenos Aires, Argentina.

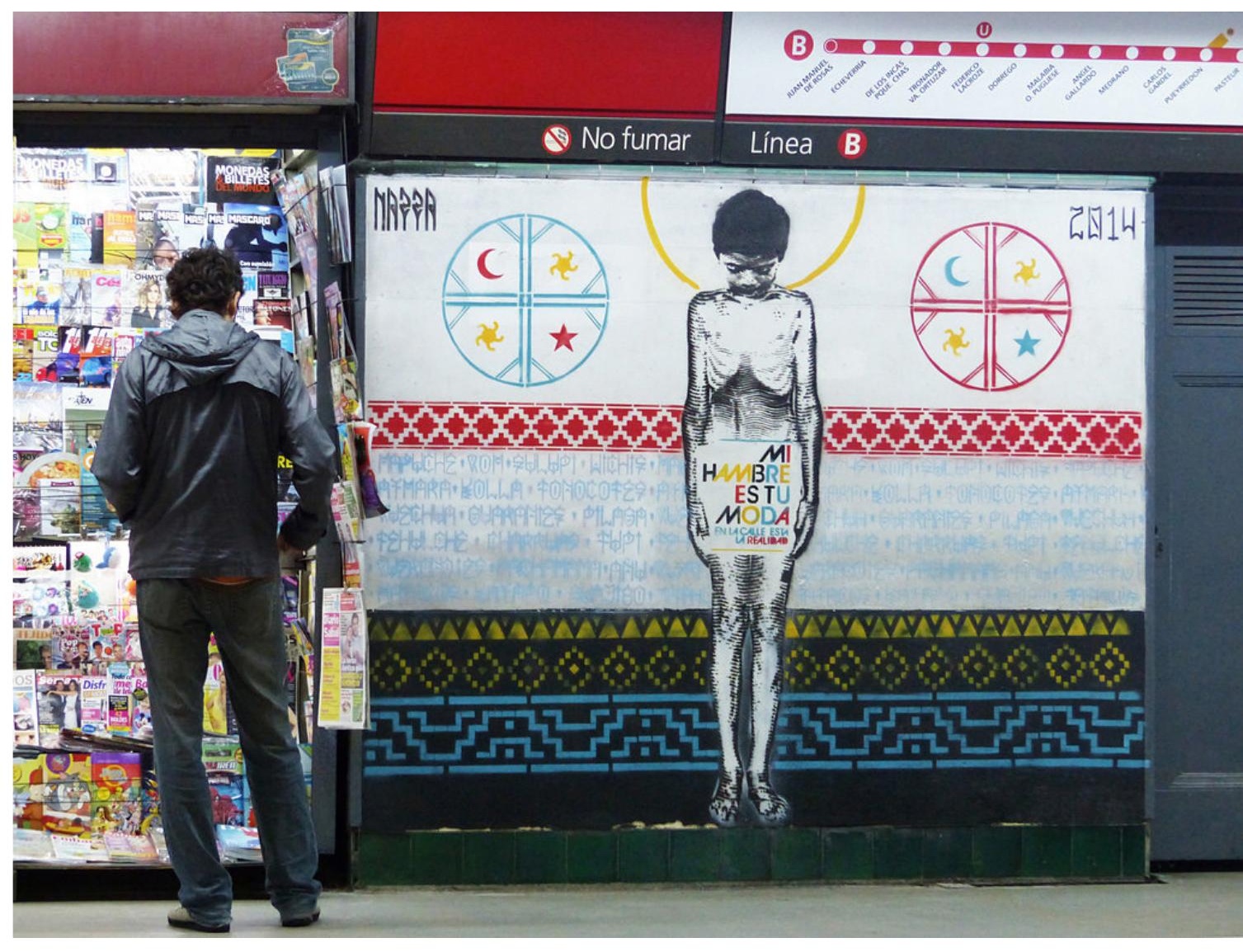


No livro Disputas em torno do espaço urbano - Processos de [re]produção/ construção e apropriação da cidade há um artigo que versa sobre as dinâmicas e disputas territoriais na cidade de Buenos Aires. Os autores Maria Mercedes de Virgilio e Mariano Perelman mostram como o próprio modo como as pessoas podem circular pelas cidades, reproduz essa disputa de maneira violenta.

Os modos de habitar, transitar e circular na cidade - também no âmbito de reprodução social - contribuem para (re)produzir as desigualdades sócio-urbanas. [...] As desigualdades são socialmente produzidas e têm manifestações e articulações espaciais claras que, por sua vez, se nutrem dela. (PERELMAN, VIRGILIO, 2017, p. 354)

Os territórios urbanos são disputados não somente espacial, mas simbólica e politicamente. Ocupar um determinado espaço dentro da cidade, mais do que uma questão de ordem, é uma questão de disputa. E, como desenvolvem mais à frente em seu artigo, os autores entendem que em estruturas modernas e pós-modernas a nossa própria construção de identidade e espaço vem a partir de uma negação ou exclusão do outro.

Dessa forma, podemos entender que a ocupação de muros em locais nobres da cidade apropriados por Nazza são principalmente uma maneira de retomar a possibilidade de transitar e experimentar uma parte da cidade, que é negada a alguns corpos, seja pela sua origem, seja pela sua classe social.

Figura 4 Nazza, 2018, Favela Complexo da Maré, muralismo, 2,00 x 2,50 mts. Rio de Janeiro. Fonte: https://www. instagram.com/ nazza.stencil/

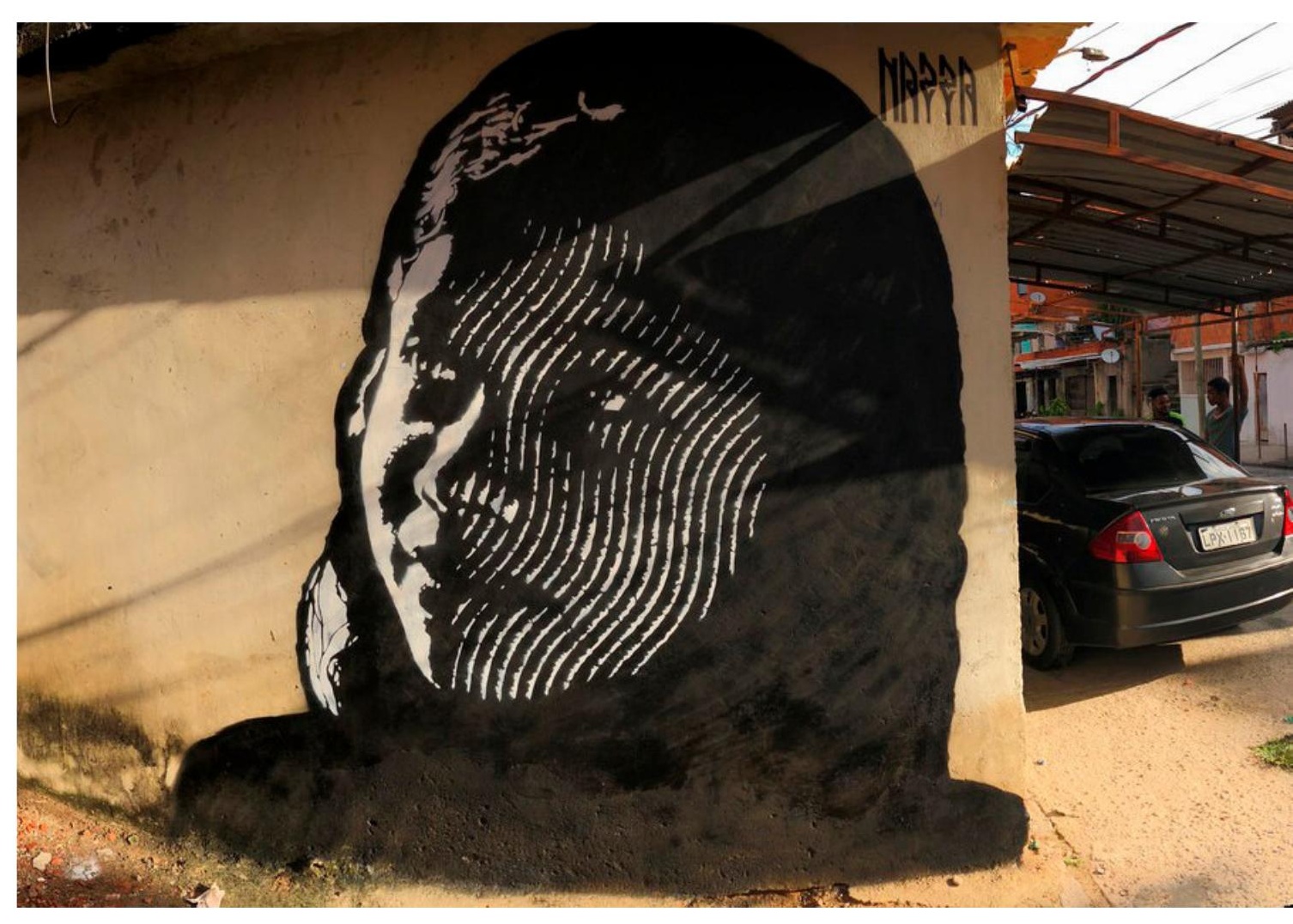


Figura 5

Nazza Stencil, 2015. \#Ni una a menos. Muralismo, $4,60 \times 2,00 \mathrm{mts}$. Cidade de La Plata, Argentina. Fonte: https://www. instagram.com/ nazza.stencil/
Quando esteve no Rio de Janeiro, por exemplo, Nazza fez questão não só de deixar obras na Rocinha, Vidigal e Complexo da Maré, mas também no Arpoador e no Leblon. Podemos entender os deslocamentos do artista e a instauração de obras que causam um certo desconforto como uma atitude de (re) apropriação do espaço e de interrupção de uma situação de invisibilidade. Já que os atores em si não podem estar lá, ele os reproduz, transfigurando a utilidade dos muros da cidade. Ele não está sozinho, nem é o único a utilizar seu próprio deslocamento como reverberação de um deslocamento mais amplo, todavia, é justamente essa tentativa de romper com o preestabelecido - como De Virgílio e Perelman ressaltam de alguns movimentos urbanos, que fazem com que Nazza se destaque entre os demais artistas políticos contemporâneos, na reconstrução do imaginário latino-americano.

Em 2015, pintou um mural na Cidade de La Plata para lembrar o horror do assassinato de Chiara Páez, que tinha 14 anos e estava grávida. Ela morava na cidade de Rufino, Santa Fé, Argentina. Seu corpo foi encontrado enterrado no pátio da casa do namorado, apenas dois anos mais velho, que foi detido com outras quatro pessoas, três delas parentes do garoto. $O$ novo femicídio, se soma a vários casos de alto impacto nos últimos meses.

CHIARA PAEZ - 14 AÑOS

$3 \times$

\section{$8 \%$ \%} $8 \% \% \% \div \%$

.
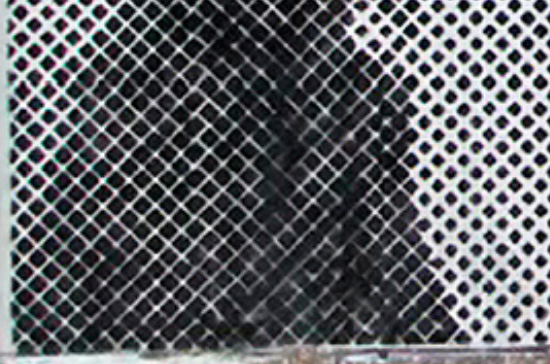

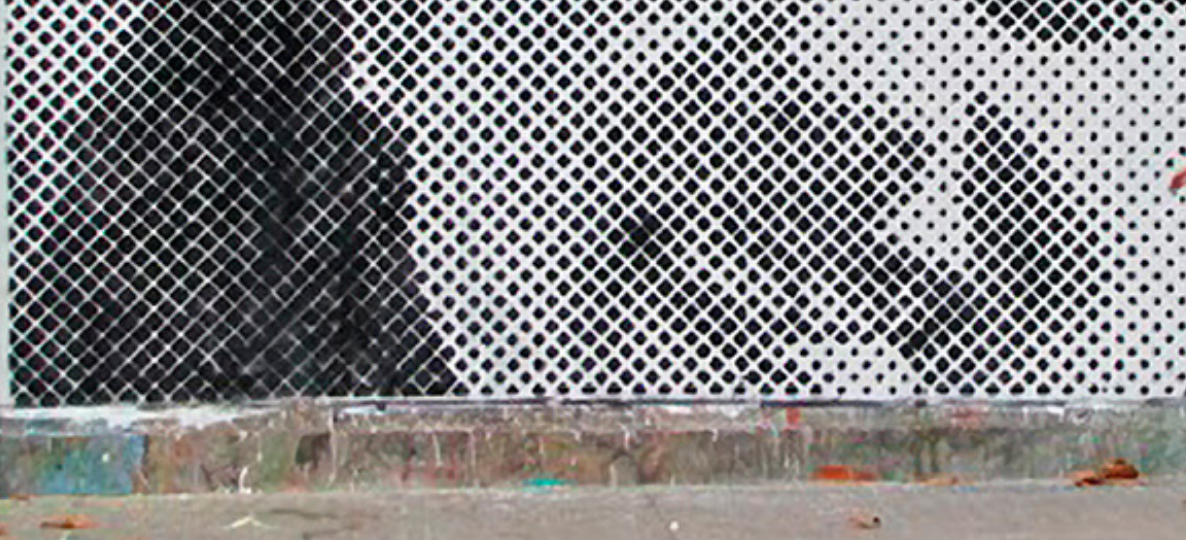
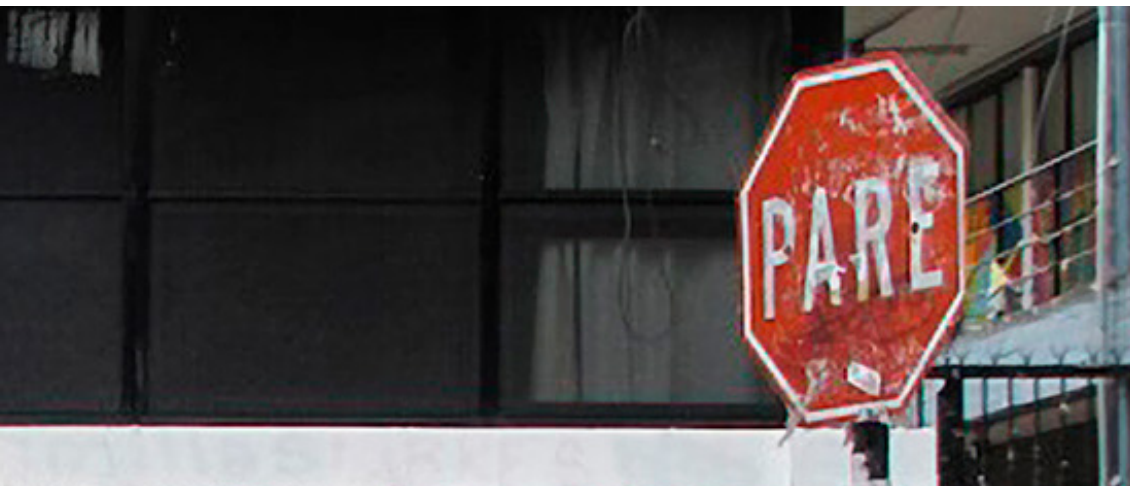

BNI UNA MENOS

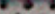

BNI UNA

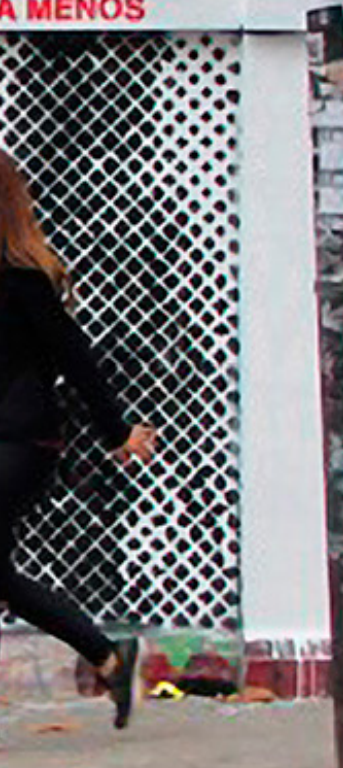

9

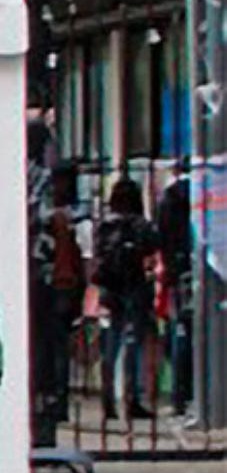


O artista também trabalha com diversas plataformas como vídeos, stopmotions e exercita um trabalho de recriação com seus próprios stencils. Apesar de ter um trabalho autoral facilmente identificável, procura se renovar regularmente e incorporar novas técnicas, assim como temáticas que julga pertinentes para discutir as desigualdades latino-americanas, que testemunha em suas frequentes viagens pelo continente.

\section{As tecnologias digitais de comunicação como forma de resistência}

Se considerarmos a não existência de um definitivo tempo do agora, pois todo presente é uma mistura de tempos diferentes, podemos refletir que uma era anterior serve de referência, enquanto a atual sonha com o que virá a seguir. Logo, não existe uma transição linear entre elas e, desse modo, também não existe uma transição pontual entre a era moderna, pós-moderna e a contemporânea. Uma perpassa pela outra e algumas características de uma, ora se afastam ora se aproximam, e reforçam conceitos.

Observá-las em conjunto possibilita, por conseguinte, perspectivas mais abrangentes para a compreensão do modo como a tecnologia, a política, e as idiossincrasias do "eu" foram se movendo para explicar as renovadas relações entre arte, vida e política, através de alguns significativos artistas e coletivos, engajados em sensíveis questões sociais pelas ruas do Rio de Janeiro e Buenos Aires, como é o caso de Nazza e Pato.

Hal Foster, no livro O retorno do real, analisa como as obras contemporâneas se aproximam do debate político não ao romper com a ordem, mas ao expô-la como crise. Para o autor:

O esgotamento das definições restritivas das relações entre arte e artistas, identidade e comunidade, também foram provocados pela pressão dos movimentos sociais, bem como dos desenvolvimentos teóricos. (FOSTER, 2014, p. 174).

Nesse sentido tanto Nazza como Pato se aproximam das ideias de Foster, pois as obras de ambos ao invés de indicarem respostas, sugerem novas perguntas ao darem visibilidade a temas sensíveis sobre corpos, delimitação de territórios, raízes e desigualdades sociais.

Todas estas questões refletem o quanto a arte se encontra, na atualidade, num limite, ou talvez, numa encruzilhada, entre a acomodação e a ressignificação de suas funções e potências, no sentido de ampliar o debate sobre temas sociais fundamentais sobre a situação de vários grupos de minorias 
étnicas e regionais, que estiveram por muito tempo deslocados e reduzidos.

Sob este cenário é preciso operar as tecnologias digitais de comunicação de modo intenso e inovador como forma de resistência. Afinal, elas permitem a descentralização do controle geral da circulação e abrem espaço de visibilidade para que os trabalhos de artistas, como os dois aqui analisados, alcancem novas fronteiras para além dos muros e ruas onde se encontram suas obras. Assim, podemos pensar em um resgate cultural e político não somente de $\mathrm{Na}$ zza e dos artistas argentinos, mas também de Pato e dos artistas brasileiros.

É urgente habitar e ocupar espaços, porque a questão fundante da estrutura social e política da América Latina permanece a mesma ao longo dos muitos anos de sua história - a da não reparação da escravidão, do extermínio dos povos originários e da dominação de uma força externa como se estivéssemos sempre transitando ao redor dos problemas sem efetivamente enfrentá-los, sem reestruturar a sociedade. Através deste posicionamento, a pesquisadora Maria Angelica Melendi propõe uma cartografia da reconstrução que seria um conjunto de reflexões artísticas, teóricas e políticas.

É preciso circular por esses lugares e tentar fazer uma passagem entre o que é seguro, cotidiano, e o que é incerto, ainda a ponto de ser descoberto. Esse processo geraria uma sensação de 'despaisamento', um estado de apreensão que induziria a uma intensificação perceptiva: de repente, o espaço assume um sentido, a possibilidade de uma descoberta... (MELENDI, 2017, p. 307)

A partir dessa maneira de entender a relação entre arte e política, podemos pensar na autora como alguém que propõe que a obra política, ela mesma, seja objeto de análise, mas não somente isso: um catalisador que fará com que o observador e o pesquisador passem por uma nova experiência estética e política. Desse modo, as duas áreas precisam caminhar a passos largos e sempre juntas, assim podemos, então, pensar em grandes conceitos que foram trabalhados nesse artigo, sem qualquer pretensão de esgotá-los, porém com um olhar indicativo de mudanças estruturais: redes de sociabilidades, território, identidade, resistência e a própria construção da arte política de rua na contemporaneidade.

\section{As possibilidades do artivismo nas ruas da América do Sul}

A concluir, analisamos o trabalho de dois artistas sul-americanos que têm como objetivo central de suas obras a discussão política territorial, identitária, de possibilidade de deslocamento nas grandes cidades sul-ameri- 
canas e de arte como objeto de resistência. Suas obras estão nos muros como vitrines de sua produção artística, mas também como palanques e espaço de reflexão e denúncias, porque ambos têm suas trajetórias construídas no encontro entre artes e política.

Suas trajetórias intensamente focadas em temas sociais, abordando questões sensíveis e, em vários aspectos, frágeis ao sistema político, jogam luz sobre a importância da relação arte-política sem que esta perca a capacidade de ser impactante enquanto narrativa visual. Suas imagens ultrapassam a mera descrição dos fatos, incomodando e propondo questionamentos que muitos já haviam naturalizado como normais, quando, de fato não são. Seus trabalhos enfim, possibilitam ver o que se tornou invisível a muitos.

Se pensarmos em situações atuais como a ocorrida em 2018 na Exposição "Arte, Democracia, Utopia - quem não luta tá morto" realizada no MAR (Museu de Arte Moderna no Rio), na qual a mesa de debate proposta pelo Amò ${ }^{1}$ para o último dia do evento foi cancelada sem maiores justificativas, podemos entender que o espaço do Museu enquanto instituição do saber, embora venha tentado se atualizar, ainda esbarra em questões objetivas, e também subjetivas, ligadas a patrocínios e orçamentos.

As ruas e as fachadas dos prédios se afirmam como grandes murais para os artistas trabalharem questões consideradas polêmicas pela sociedade e, desse modo, além de alcançarem um público mais amplo conseguem estimular e reativar questões ligadas à formação do Estado-nacional enquanto nação e os problemas gerados em sua construção. Segundo Tania Alice e Gilson Mota, o artivismo é “... ideia de uma arte pública que engloba a resistência cultural e militância social, política, espiritual e ecológica”. (MOTTA; ALICE, 2012, p. 38)

Ambos autores apostam na possibilidade de existir uma arte política e engajada em um mundo em ruínas (não estamos falando somente da economia em crise, mas dos próprios padrões e contratos sociais que são postos em cheque com o novo modelo de plataformização, ou ubberização do trabalho, com as inúmeras flexibilizações que retiram inúmeros direitos trabalhistas por uma situação de precariedade formal nas relações laborais).

1 Uma ação coletiva composta pelas artistas: Ana Lira, Marina Alves, Marta Supernova, Thais Rocha e Thais Rosa 
A atuação, dessa forma, precisa estar fundamentada em uma micropolítica capaz de atravessar cidades e corpos sem precisar de uma estrutura física e monetária grandiosa. Nesse sentido, as manifestações de Nazza e Pato possuam mais aderência, pois conseguem transitar com mais facilidade e ocupam um espaço gratuito. Diferentemente, por exemplo, de artes como o cinema e grandes produções teatrais.

Não estamos defendendo o fim do sistema de artivismo ou ativismo político centrado nessas artes que possuem um sistema de mercado por detrás de suas produções, mas notamos que é preciso urgência e propagação do discurso. Qual melhor maneira de fazê-lo a não ser nas ruas das próprias cidades? Tanto Nazza quanto Pato fazem uma inversão reinventada de corpos e territórios - como já propunha o pintor uruguaio Joaquin Torres García, com seu mapa invertido², no início do séc. XX, porque se o centro comercial e cultural da cidade não vai até as regiões mais pobres, essas regiões e pessoas se reconhecem quando são representadas nos espaços públicos das cidades. Precisamos, então, como já preconizava Torres García, fazer do nosso Sul, o nosso Norte, ou seja, olhar mais ao redor para a produção dos países que compõe o continente Latino-Americano, ampliar os contatos, divulgação e sua valorização.

Esse trabalho centrou a atenção para as potências e significações simbólicas de obras originárias das ruas de Buenos Aires, Argentina e Rio de Janeiro, Brasil, mas como o início de nossa reflexão aponta, essa situação é enfrentada pela América Latina como um todo. É evidente que cada país guarda suas particularidades, mas em um momento no qual tanto a economia, quanto qualidade de vida parecem decair vigorosamente, é importante dar maior visibilidade a obras que tragam este tipo de saudável inquietação. Elas permitem novas percepções, frente ao atual cenário de aumento das desigualdades sociais, abusos de poder e de um generalizado desmonte cultural, onde até censura a livros tentou-se implementar - secretaria de Educação do Governo de Rondônia, em fevereiro de 2020.

Parece-nos, enfim, que os tempos de crises aumentam a potência e significações simbólicas dos fazeres artísticos que tem a relação 'artes e política - políticas e arte' como tema. Muitas questões deste tipo de manifesta-

2 América Invertida desenho de caneta e tinta de 1943 do artista relacionado ao "Manifesto da Escola do Sul" que buscou reunir no início do século XX intelectuais e artistas latino-americanos. 
ção artística se dirigem a pontos que afetam de modo sensível variados grupos. Num momento em que os temas de gênero, raça, rejeição e falta de sensibilidade aos grupos originários - como os indígenas, passaram a estar presentes em muitos debates junto com as demandas sociais, temos a ampliação e ao mesmo tempo o redescobrimento da orientação trazida nos anos 60 , pelo movimento de libertação das mulheres, de que o pessoal é político, e nessa configuração, as artes tem um papel de destaque a cumprir. Afinal, não faz mais sentido manter visões fragmentadas da realidade e desviar os olhares para o contexto geral de sociedade. E os trabalhos artísticos-políticos apresentados neste texto são signos e símbolos dessas lutas que as ruas e os espaços públicos podem promover, pela reverberação expressiva que possibilitam.

\section{Referências}

CANCLINI, Nestor Garcia. O mundo inteiro como lugar estranho. São Paulo: Edusp, 2016.

DE VIRGILIO, Mercedes e PERELMAN, Mariana. Dinâmicas territoriais na produção da desigualdade em Buenos Aires. In: Disputas em torno do espaço urbano - Processos de [re]produção/construção e apropriação da cidade. Bahia: UFBA, 2017.

FOSTER, Hal. O retorno do Real. São Paulo: CosacNaify, 2014.

MELENDI, Maria Angélica. Estratégias da arte em uma era de catástrofes. Rio de Janeiro: Codogó, $1^{\text {a }}$ reimpressão, 2017.

MOTTA, Gilson e ALICE, Tania. Artivismo e utopia no mundo insano in Revista ArteFilosofia (UPOF), número 12, 2012.

\section{Sítios Eletrônicos:}

ALEMAN, Gabriela. Equatoriana Gabriela Alemán escreve sobre os protestos que paralisaram seu país. Folha de São Paulo, São Paulo, 24.dez.2019. Disponível em: https://www1.folha.uol.com.br/mundo/2019/12/equatoriana-gabriela-aleman-escreve-sobre-os-protestos-que-paralisaram-seu-pais.shtml, acesso em 11 de janeiro de 2020.

ARTE URBANA WORLD , Arte Urbana: o que as ruas dizem-Stencil Art , 15 de agosto de 2015 https://arteurbanaworld.wordpress.com/category/ stencil/\#, acesso em 13 de fevereiro de 2020

BETIM, Felipe. Quero dar voz a quem nunca teve: o grafiteiro que exalta o povo 
nordestino nas ruas da periferia do Rio. El Pais, Rio de Janeiro, 21 de agosto de 2017 Diponível em: https://brasil.elpais.com/brasil/2018/07/31/cultura/1532996996_717301.html, acesso em 20 de janeiro de 2020.

CASTIGLIONI, Rossana. Superando o estouro chileno por meio de uma nova Constituição. Folha de São Paulo, São Paulo, 22 novembro 2019. Disponível em: https://www1.folha.uol.com.br/mundo/2019/11/superando-o-estouro-chileno-por-meio-de-uma-nova-constituicao.shtml, acesso em 08 de fevereiro de 2020.

COLOMBO, Sylvia. Efeito-contágio de protestos e crise acendem alerta na América Latina. Folha de São Paulo, São Paulo, 14.dez.2019. Disponível em: https://saopaulo.folha.uol.com.br/revista/2019/12/efeito-contagio-de-protestos-e-crise-acendem-alerta-na-america-latina.shtml, acesso em 20 de janeiro de 2020.

D’ÁVILA, Sergio. Bárbaros no portão, Folha de São Paulo, São Paulo, 16 de abril de 2020. Disponível em: https://www1.folha.uol.com.br/opiniao/2020/04/barbaros-no-portao.shtml, acesso em 16 de abril de 2020. NAZZA, Stencil. Site profissional: https://nazza-stencil.com/, acessado em 23 de janeiro de 2020. . Grafitimundo, Nazza Stencil https://graffitimundo.com/artists/ nazza-stencil-3/, acesso em 02 de fevereiro de 2020.

PATO, Walllace. Instagram do artista: https://www.instagram.com/wallace.pato/, acessado em 10 de fevereiro de 2020. 